\section{Case Reports in Neurology}

Case Rep Neurol 2021;13:140-144

DOI: 10.1159/000512405

Published online: February 26, 2021

(c) 2021 The Author(s)

Published by S. Karger AG, Basel

www.karger.com/crn

This article is licensed under the Creative Commons Attribution-NonCommercial 4.0 International License (CC BY-NC) (http://www.karger.com/Services/OpenAccessLicense) Usage and distribution for commercial purposes requires written permission.

\title{
Horizontal Gaze Defect as a Result of Subcortical Stroke: Case Report and Review of the Literature
}

\author{
Abdulrahman M. Alshahrani \\ Department of Internal Medicine (Neurology), College of Medicine at Shaqra, Shaqra \\ University, Shaqra, Saudi Arabia
}

\section{Keywords}

Gaze palsy · Saccadic and pursuit system · Stroke

\begin{abstract}
Gaze palsies are commonly observed in the setting of acute stroke; such strokes are nearly always localized to either cerebral cortical or brainstem areas. Much less common are lesions localized at the subcortical pathways involved in the control of eye movements. We report a patient with subcortical white matter ischemic stroke who suffered horizontal gaze defects.

(C) 2021 The Author(s)

Published by S. Karger AG, Basel
\end{abstract}

\section{Introduction}

Acute strokes are commonly associated with visual impairments. Horizontal gaze defects are seen frequently in such patients. The typical anatomical locations of such lesions are usually seen at a cerebral cortex or brainstem level. On rare occasions, horizontal gaze defects result from strokes localized to the subcortical gaze controlling pathways. This article describes such a case.

\begin{tabular}{ll}
\hline & Dr. Abdulrahman M. Alshahrani \\
Department of Internal Medicine (Neurology) \\
College of Medicine at Shaqra, Shaqra University \\
Shaqra 11961 (Saudi Arabia) \\
alshahrani.md@su.edu.sa
\end{tabular}




\section{Case Reports in Neurology}

\section{Case Report}

A 62-year-old right-handed male with a longstanding history of diabetes mellitus and hypertension presented with sudden-onset left-sided body weakness as well as a loss of feeling over the left side of his body. These symptoms started approximately 3 days before the presentation to the hospital. He gave a history of difficulty looking to the left side as well. There was no history of loss of consciousness, speech difficulties, seizures, headaches, or vomiting. His neurologic examination showed an intact level of consciousness, normal higher mental functions as well as normal speech. The examination of vision showed conjugate horizontal left gaze palsy. He could maintain gaze near mid-position but could not cross the midline to the left side. Doll's head maneuver brought the eyes past the midline to the left. Visual acuity was normal at the bedside near-fixation test. Visual fields were assessed by bedside confrontation methods and did not show clear defects. Examination of facial nerves showed weakness of the upper motor neuron type on the left side, and the remainder of cranial nerves was intact.

Motor system examination showed hypotonia, hemiplegia, hyporeflexia as well as extensor plantar response on the left side of the body. Sensory system examination showed left hemisensory loss of pain and temperature sensations.

Computed tomography scan of the brain showed an area of infarction over the right subcortical corona radiata region (Fig. 1). He received inpatient stroke care and then was discharged home.

He was re-assessed in the neurology outpatient clinic (OPD) at 1,3, and 6-month intervals after discharge. Neurologic examination on the first visit to the neurology clinic showed some improvement in the range of eye movements; however, he had residual partial defects of both saccadic and pursuit functions on horizontal gaze. His motor power over the left side of his body was better as compared to his baseline. Tone and deep tendon reflexes were increased over the left side as well, and the other neurologic findings were the same as his baseline.

His neurologic assessment on the second visit to the neurology OPD did not show significant changes from the first visit. However, re-assessment on the third visit (i.e., 6 months after discharge) showed complete recovery of gaze palsy, better motor power on the left side of his body with otherwise similar findings as before.

\section{Discussion}

The prevalence of visual impairments following strokes varies widely among different studies. The reasons are related to the setting of the research conducted, the patient cohort, the longevity of stroke, and antecedent eye disorders.

In a systematic literature review of types of visual impairments following a stroke, the overall prevalence of such impairments was estimated at 65\% (ranging from 19 to 92\%) [1].

In a recent multicenter prospective epidemiological study in acute stroke units, it was found that the prevalence of visual problems ranged from $58 \%$ for all stroke admission to $73 \%$ for all stroke survivors [2].

\section{Karger'=}




\section{Case Reports in Neurology}

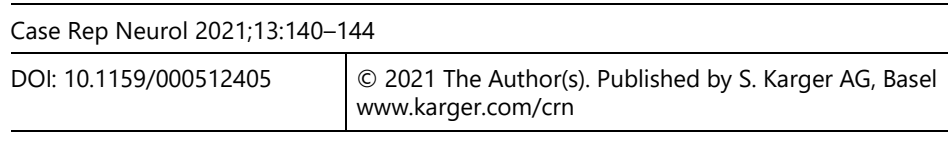

Alshahrani: Horizontal Gaze Defect

There is a wide range of visual disorders that occur following a stroke, and ocular movement abnormalities are considered as some of the most common types of such disorders [39].

Our patient demonstrated both saccadic and pursuit defects at the same time, supporting the hypothesis of a common pathway that controls both systems. Many of the subcortical pathways of conjugate gaze-controlling mechanisms are not well understood and only presumed to exist [8].

The fact that some frontal lesions are associated with ipsi-directional pursuit defects in conjunction with contraversive saccade disorders supports the concept that both systems operate via a common cortical-subcortical-brainstem pathway. However, the observation of frontal lesions with isolated contralateral saccade defect and normal pursuit weigh against a common pathway [9].

Our patient demonstrated abnormalities of the horizontal gaze (saccadic and pursuit defects). Gaze palsy can be divided into disorders of vertical or horizontal gaze and further into nuclear (disconjugate) or supranuclear (conjugate) lesions. Horizontal gaze palsies can be divided into saccadic or pursuit defects. Saccadic and pursuit systems are concerned with conjugate eye movements. Table 1 summarizes the basic characteristics of both systems [10-12].

In the case of strokes, restriction of horizontal gaze on one side is usually due to damage of the contralateral frontal cortex or ipsilateral pontine area. Our patient had a stroke lesion located in the subcortical white matter area; such location is not commonly reported in the literature as a cause of horizontal gaze palsy.

Lesions in the corona radiata adjacent to internal capsule may cause horizontal gaze defects. Fukutake et al. [13] reported a patient with contralateral selective saccadic palsy after a small hematoma in the corona radiata.

\section{Conclusion}

Conjugate horizontal gaze palsy is uncommon but not unusual in cerebral subcortical white mater stroke. In such a case, the presence of both saccadic and pursuit defects at the same time indicates a probable common pathway that controls both systems. A larger-scale basic and clinical research is warranted.

\section{Acknowledgement}

The author is thankful to Shaqra University for developing and encouraging the research platform to serve the community and world.

\section{Karger'=}




\section{Case Reports in Neurology}

Case Rep Neurol 2021;13:140-144

DOI: $10.1159 / 000512405$

2021 The Author(s). Published by S. Karger AG, Basel www.karger.com/crn

Alshahrani: Horizontal Gaze Defect

\section{Statement of Ethics}

The paper is exempt from ethical committee approval. This is a case report study and does not include the experiment on animal and human subjects.

Written informed consent was obtained from the patient for publication of this case report and accompanying image.

\section{Conflicts of Interest Statement}

The author has no conflicts of interest to declare.

\section{Funding Sources}

None.

\section{References}

1 Hepworth L, Rowe F, Walker M, Rockliffe J, Noonan C, Howard C, et al. Post-stroke Visual Impairment: A Systematic Literature Review of Types and Recovery of Visual Conditions. Ophthalmology Research: An International Journal. 2016;5(1):1-43.

2 Rowe FJ, Hepworth LR, Howard C, Hanna KL, Cheyne CP, Currie J. High incidence and prevalence of visual problems after acute stroke: an epidemiology study with implications for service delivery. PLoS One. 2019 Mar;14(3):e0213035.

3 Rowe FJ; VIS writing Group. Vision In Stroke cohort: profile overview of visual impairment. Brain Behav. 2017 Oct; 7(11):e00771.

4 Rowe FJ, Wright D, Brand D, Jackson C, Harrison S, Maan T, et al. Profile of Gaze Dysfunction following Cerebrovascular Accident. ISRN Ophthalmol. 2013 Oct;2013:264604.

5 Rowe F, Brand D, Jackson CA, Price A, Walker L, Harrison S, et al. Visual impairment following stroke: do stroke patients require vision assessment? Age Ageing. 2009 Mar;38(2):188-93.

6 Fowler MS, Wade DT, Richardson AJ, Stein JF. Squints and diplopia seen after brain damage. J Neurol. 1996 Jan;243(1):86-90.

7 Ciuffreda KJ, Kapoor N, Rutner D, Suchoff IB, Han ME, Craig S. Occurrence of oculomotor dysfunctions in acquired brain injury: a retrospective analysis. Optometry. 2007 Apr;78(4):155-61.

8 MacIntosh C. Stroke re-visited: visual problems following stroke and their effect on rehabilitation. $\mathrm{Br}$ Orthopt J. 2003;60:10-4.

9 Freeman CF, Rudge NB. Cerebrovascular accident and the orthoptist. Br Orthopt J. 1988;45:8-18.

10 Christopher G. Textbook of Clinical Neurology. 3rd ed. Philadelphia: W.B. Saunders; 2007.

11 Brazis PW, Masdeu JC, Biller J. Localization in clinical neurology. 5th ed. Philadelphia: Lippincott Williams \& Wilkins; 2006.

12 Patten J. Neurological Differential Diagnosis. 2nd ed. London: Springer-Verlag London; 1996.

13 Fukutake T, Hirayama K, Sakakibara R. Contralateral selective saccadic palsy after a small haematoma in the corona radiata adjacent to the genu of the internal capsule. J Neurol Neurosurg Psychiatry. 1993;56(2):221. 


\section{Case Reports in Neurology}

\begin{tabular}{l|l}
\hline Case Rep Neurol 2021;13:140-144 \\
\hline DOI: 10.1159/000512405 & $\begin{array}{l}\text { (c) 2021 The Author(s). Published by S. Karger AG, Basel } \\
\text { www.karger.com/crn }\end{array}$ \\
\hline
\end{tabular}

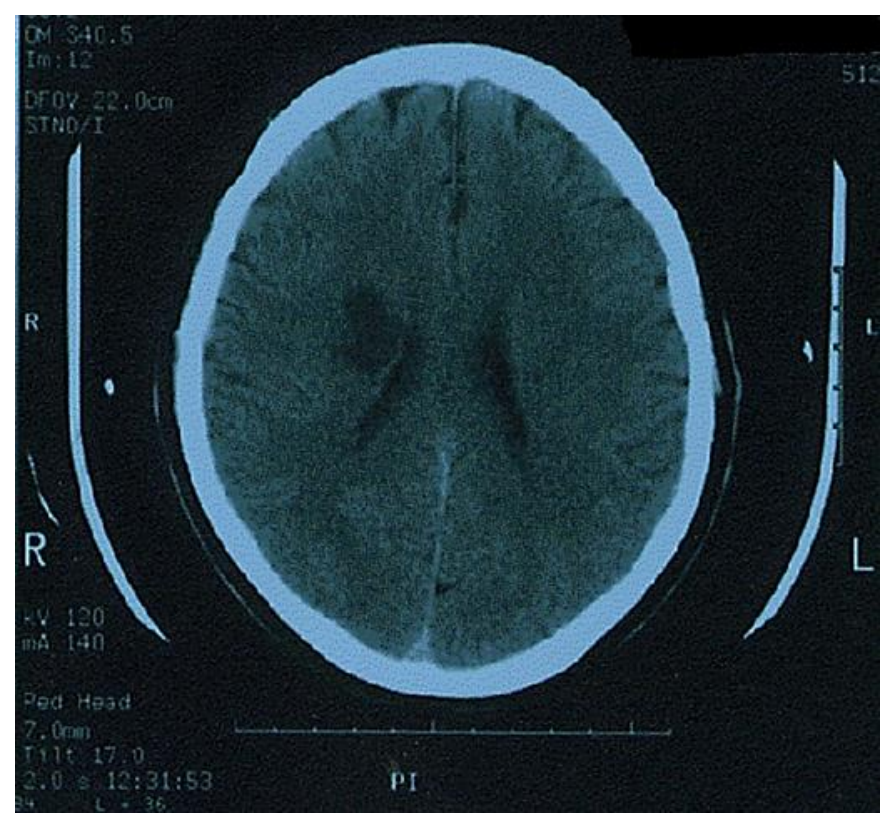

Fig. 1. Computed tomography scan of the brain axial cuts showing a well-demarcated hypodense lesion consistent with ischemic infarction on the right centrum semiovale.

Table 1. Basic characteristics of saccadic and pursuit systems

\begin{tabular}{lll}
\hline & Saccadic system & Pursuit system \\
\hline Anatomical cortical areas & $\begin{array}{l}\text { Frontal eye field } \\
\text { Supplementary eye field } \\
\text { Parietal eye field } \\
\text { Prefrontal cortex } \\
\text { Posterior parietal cortex }\end{array}$ & $\begin{array}{l}\text { Partially unknown } \\
\text { Occipital visual area provides inputs to the areas }\end{array}$ \\
\hline Anatomical decussation & $\begin{array}{l}\text { Decussate between diencepha- Not clearly known } \\
\text { lons and pons }\end{array}$ & Either do not decussate or undergo double decussation \\
\hline Speed of action & Rapid & Slow \\
\hline Mechanism of control & Voluntary & Involuntary \\
\hline Direction of control & Contraversive & Ipsiversive \\
\hline
\end{tabular}

